$\xi_{3}$

\title{
Role of Energy Efficiency and Conservation Including Demand Side Management for Sustainable Development in India
}

\author{
Rakesh Kumar ${ }^{1}$, Rakesh Ranjan ${ }^{2}$, Mukesh Chandra Verma ${ }^{3}$ \\ ${ }^{2}$ Professor, ${ }^{1,2,3}$ Himgiri Zee University \\ *Corresponding Author Email: ${ }_{3}^{1}$ ra77kesh@gmail.com ,' 2 rakesh.ranjan@hzu.edu.in \\ ${ }^{3}$ mukeshverma20@yahoo.com
}

\begin{abstract}
Energy is used to provide cost-effective services meet the objectives of promoting sustainable development. The importance of Energy Efficiency and Conservation (EE and EC) is to conserve depleting energy resources. Energy efficiency in India has been increasing which has led the Government of India through the Energy Conservation Act (ECA) and the Bureau of Energy Efficiency (BEE) to begin several programs. Demand Side Management (DSM) and Energy Efficiency and Conservation are improving the economic growth of Indian utilities.DSM also aimed at promoting the installation and use of energy efficient equipment that consume less power having good quality of output. Energy efficiency is important for sustainable future. Demand Side Management including Demand Response (DR) Activity is utilized to limit the peak electricity demand. DSM helps grid operators to act as virtual power plants and power the utilities to transmit energy when needed through demand response measures. Demand Response (DR) measures can be adapted for a industrial and commercial facility that includes turning off air conditioning, lighting, pumps, and other non-essential equipment. Demand Response is a Demand Side Management (DSM) method in which the end users of electricity are encouraged to take part in dropping the peak load on the system by altering their normal energy consumption schedule. The basic objective of the Agriculture, Municipal and Industrial Demand Side Management (DSM) programmes are to improve the overall energy efficiency of the SLDC (State Load Dispatch Centre) and Electricity Grids which could lead to substantial savings in the electricity consumption, resulting in cost reduction and savings. The target of energy saving can be achieved by implementing acts and policies which leads to state wise DSM Regulations by Regulatory Commissions to the State Power Utilities. The Role of DSM and Energy Efficiency including conservation can fulfill the dreams projects electricity demand in Smart Cities. The Role of State Electricity Regulatory Commissions and Forum of Regulators are very important to make India's electricity demand in future.
\end{abstract}

Keywords: DSM, SLDC, SERCs.

\section{Introduction}

Electricity is generated by burning coal, by a nuclear reaction, or by a hydroelectric plant on a river through reservoir using rotation of turbine. Nowadays, Electricity is one of the prime source for internet access, digitalization of Government offices under Digital India mission. Industries are main segments where electricity is highly required throughout the day and night for continuous production and fulfill the demand of peoples. For handling peak load demand some States have issued DSM Regulations and DISCOMs are actively working on it. Several beneficiary programs are being implemented to cater Time of Day (ToD) Tariff, Power Factor incentives, etc. Several State Governments have issued orders for promoting Energy Efficiency (EE) and Energy Conservation (EC) missions. Forum of Regulators are actively working on save energy mission and issuing time to time guidelines to State Electricity Regulatory Commission's (SERCs), Power Utilities, Distribution Companies (DISCOMs) and State Load Dispatch Centre's (SDLCs).

\section{Literature Review}

Energy conservation is important to decrease peak and average demand of energy. The energy conservation is possible with the execution of technology to save energy. By improving end user's efficiency using Demand Side Management the amount of energy consumption can be reduced. Sustainable Development is a systematic principle for achieving human development goals. The main features of sustainable energy development are:

- Energy Efficiency improvement programs;

- Satisfaction of human needs;

- $\quad$ Shifting towards Renewable Energy resources

Energy Conservation is playing important role in Energy Efficiency without affecting economic growth of the country in Sustainable Development. Demand Side Management Regulations are necessary to frame and SERCs monitoring is necessary to work on it. The gap between energy generation and demand is high which can be minimized by improving Energy Efficiency at end users. 
End user segment is a main area of conservation of energy to bridge the gap between generation and demand. Energy Conservation is important to decrease energy consumption. However, various efforts have been made till now, but their realization at ground level is necessary for Sustainable Development in India by SERCs, Distribution Companies (DISCOMs) and other Power Utilities.

\section{Methodology}

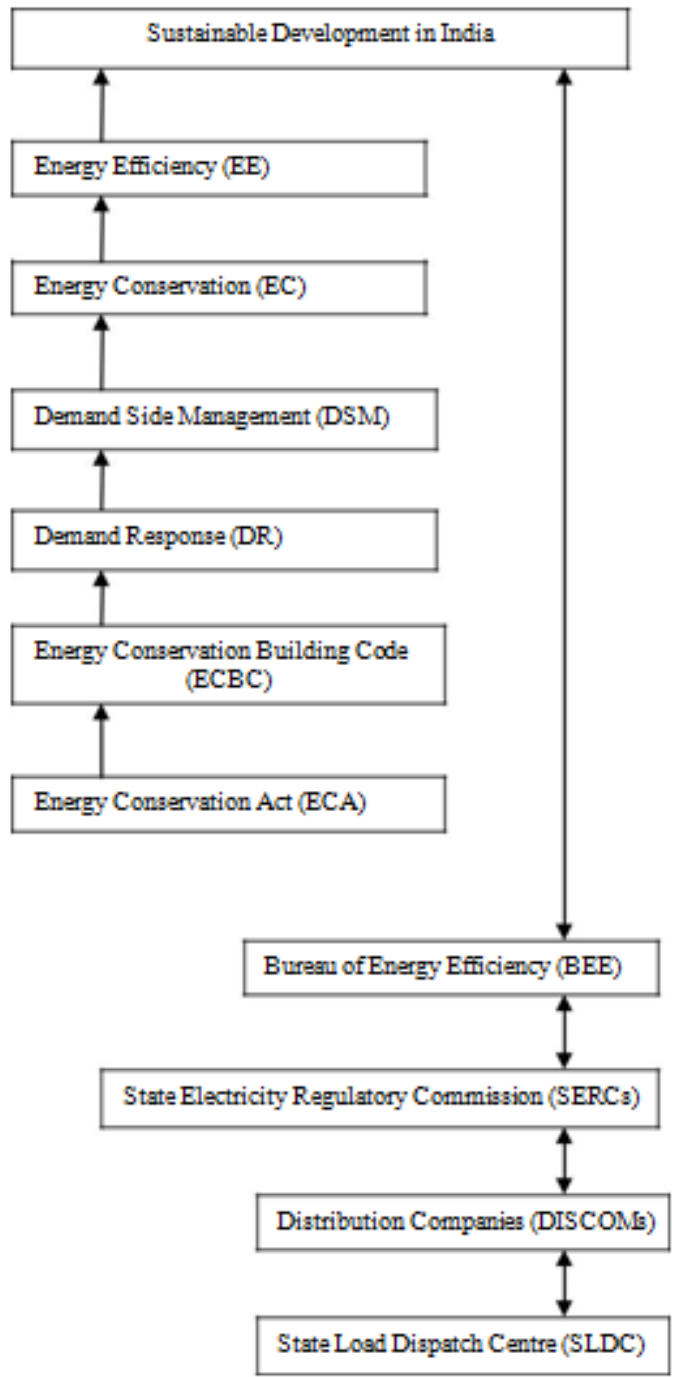

Fig. 1: Energy approach for Sustainable Development

India is one of the developing nations which is going to make its important position in 21 st Century. Technology plays important role in overall development of the Country. One of the great advantages is having full of raw materials availability with in the country. Energy is the prime source for Sustainable Development. Energy is the life blood of Country and its conservation and systematic utilization is necessary to meet energy demand with in the Country. The methodology is on two way approach:

1. Implementation of new protocols, changes technologies and methods in energy sector;

2. Role of various bodies at State and Central Level in compliance to adhere these acts rules and methods.
Table 1: DSM Programs

\begin{tabular}{|c|c|}
\hline SNo. & DSM Program \\
\hline 1. & Five Star Ceiling Fan \\
\hline 2. & T5 Tube Light \\
\hline 3. & 5 Star Split AC \\
\hline 4. & Energy Efficient Refrigerators \\
\hline 5. & Demand Response Program \\
\hline 6. & Thermal Energy Storage \\
\hline 7. & Agriculture DSM \\
\hline 8. & Municipal DSM \\
\hline
\end{tabular}

The role of DSM cells is very important in State wise Sustainable Development which can be fruitful to following:

a) Load surveys

b) Load strategies such as Demand Response,

c) Load Management Programme,

d) Dynamic/real time pricing,

e) Time-of-use rates,

f) Automated/Smart Metering,

g) Web-based/communication system

h) Demonstration studies

i) Advanced Metering

j) DSM financing

Demand Response is a DSM method in which the end users of electricity are encouraged to reducing the peak load to normal energy consumption through discount or incentive programs on their energy consumption pattern.

This helps in reduction to peak load as end-users shift the operation of their loads from peak hours or high market price hours to off-peak hours or low market price hours.

The Energy Efficiency and Conservation can be made strict to comply with the help of Demand Side Management. Following steps can be takes for saving limited resources on earth and for the promotion of Sustainable Development.

i. Association with EESL and BEE for load surveys and research,

ii. Execution of Time of Day Tariff,

iii. Installation of LED bulbs,

iv. Usage of 5 star rated appliances,

v. Usage of solar pumps in agriculture,

vi. Awareness through Electricity Literacy programs , vii. Use of Smart Grid for Load Management.

\section{Result}

India's demand for electricity is rising due to development of various Multinational Companies, Banks, State Highways, and Railway Electrification, Shopping Malls, IT Data Centre's and other heavy electricity load requirements. This demand will keep on increasing, as the population is also major factor for this increment. Energy Efficiency and Conservation very important to save energy demand for future and sustainable development of all segments in our society. Distribution Companies (DISCOMs) and Electricity Regulatory Commissions is playing very important role to cater this near future demand using Demand Side Management (DSM) programs. Several States have started DSM Program and framing regulations in accordance with their consumer patterns. The list of states is as follows:

Table 3: DSM and Energy Efficiency and Conservation implementation status State wise

\begin{tabular}{|c|c|c|c|}
\hline SNo. & State Name & DISCOM & Remarks \\
\hline 1. & Assam & APDCL & DSM Started \\
\hline 2. & Delhi & BRPL & DSM, Energy \\
\hline & & & Efficiency Programs \\
\hline & & & Started \\
\hline 3. & Jammu and & PDD & DSM and Energy \\
\hline & Kashmir & & Conservation \\
\hline
\end{tabular}




\begin{tabular}{|c|c|c|c|}
\hline 4. & Jharkhand & JUSCO & DSM Started \\
\hline 5. & Madhya & MKVVCL & DSM Started \\
\hline & Pradesh & & \\
\hline 6. & Manipur and & P and E & FOR Regulations \\
\hline & Mizoram & Department & adopted \\
\hline 7. & Tamilnadu & TANGEDCO & DSM Started \\
\hline 8. & West Bengal & WBSEDCL & DSM Started \\
\hline
\end{tabular}

DSM, Energy Efficiency and Conservation schemes in India can reduce the demand of electricity on peak time which will help in overall growth of Energy Sector. Bureau of Energy Efficiency (BEE) has setup various schemes to target the areas like households lighting, commercial buildings, standards and labeling of appliances, Demand Side Management in agricultural, municipalities, Small and Medium Enterprise (SME's) and large industries.

\section{Conclusion}

Electricity is generated at generation stations and transferred to far Grid Stations using cables. Still Electricity is continuously generated and transferred but there is huge gap between generation and demand of energy. The Conservation is critically important by changing all inefficient light fittings, lamps with efficient one. Demand Side Management helps to reduce load on the Electrical Network. Conservation of energy can be reduced by less energy consumption. Adoption of energy conservation measures is necessary to reduce effective demand and to save huge investments which reduce environmental pollutants. For Sustainable Development it is necessary to adopt best possible steps which can contribute the successful development of energy sector as well as Industrial, Agriculture and Home Sector.

\section{References}

[1] T.V. Ramachandra, "Energy Options for Sustainable Development", ENERGY MANAGEMENT RENEWABLE ENERGY, JanuaryMarch 1993, pp. 187-194.

[2] Biswajit Biswas1, Sujoy Mukherjee2, Aritra Ghosh, " Conservation of Energy: a Case Study on Energy Conservation in Campus Lighting in an Institution ", International Journal of Modern Engineering Research (IJMER), Jul - Aug. 2013, pp-1939-1941.

[3] Aditya Chunekar, Mrudula Kelkar, Shantanu Dixit, "Demand Side Management in India: An Overview of State Level Initiatives" Prayas (Energy Group), September 2014.

[4] Neeraj Arya, "Energy Conservation: Demand Side Management Energy Management Initiatives in India's Industrialized States " Energy Conservation: Demand-Side Management, Dec 14, 2017, pp. 3-17.

[5] Shakti Sustainable Energy Foundation, "Demand Side Management in India: Technology Assessment", 2014, pp 1-58. 